\title{
Utilização dos laboratórios padrão MEC nas escolas estaduais do Paraná: o que dizem estudantes e professores ${ }^{1}$
}

\author{
Use of MEC standard laboratories in state schools in Paraná: \\ what students and teachers say about it
}

\author{
El uso de laboratorios estándar MEC en las escuelas del estado \\ de Paraná: lo que dicen los estudiantes y profesores
}

\author{
Céuli Mariano Jorge ${ }^{2}$ \\ Andrea de Paula Ceccatto ${ }^{3}$ \\ Fabiana Cristina Campos 4 \\ Cícero Vieira Torres Junior 5
}

\section{Resumo}

O artigo resulta de uma pesquisa realizada em 2014, em escolas estaduais do Paraná que receberam laboratórios padrão MEC de biologia, química, física e matemática, enviados pelo Governo Federal. O objetivo foi avaliar a utilização desses laboratórios, comparar com os dados obtidos na pesquisa realizada em 2013 e discutir elementos contributivos para a melhoria da efetivação das aulas práticas. Contemplou 3.969 estudantes e 397 professores do Ensino Médio, em 127 escolas, situados em 79 municípios. Teve como suporte teórico as atuais Diretrizes Curriculares Nacionais para o Ensino Médio, as quais apontam a pesquisa como princípio pedagógico e a importância em despertar a curiosidade científica nos estudantes. Priorizou uma análise qualitativa a partir dos dados quantitativos obtidos por meio de formulário respondido pelos estudantes e professores. Os dados mostram que as escolas apresentam laboratórios bem estruturados, em espaço apropriado, porém, as aulas práticas não estão sendo realizadas, e quando se realizam, não estimulam o interesse pela investigação e a ampliação do conhecimento pelos estudantes. A análise fornece elementos para discutir os fatores que interferem na efetivação e qualidade das aulas práticas.

Palavras-Chave: Laboratório; Aulas práticas; Ensino Médio.

1 Agradecemos à Coordenação de Projetos e Processos da SEED/PR, na pessoa da Professora Laurita Menjon da Silva;à Janine Gualdessi Godinho; Silvia de Lima Matioski e Evandro José Soares pela leitura crítica e auxílio no tratamento dos dados.

2Professora da Rede Estadual de Educação do Paraná. Doutora em educação pela Universidade Federal do Paraná - UFPR. E-mail: ceulimariano@gmail.com.br

3 Professora da Rede Estadual de Educação do Paraná. Mestre em Educação pela Universidade Federal do Paraná - UFPR. E-mail: Rede Estadual de Educação do Paraná

4 Superintendente da Secretaria Estadual de Educação do Paraná - SEED. Doutora em Educação pela Universidade Federal de São Carlos - UFSCAR. E-nail: campos fabianacristina@hotmail.com

5 Técnico Pedagógico da Secretaria de Estado da Educação do Paraná - SEED. Mestre em Educação pela Universidade Federal de Juiz de Fora - UFJF 


\begin{abstract}
The present article results from a survey conducted in 2014 in state schools of Paraná which received MEC (Portuguese abbreviation) standard biology, quemistry, physics and mathematics laboratories from the Federal Government. The objectives were to evaluate the use of those labs, to compare with the data obtained in a research carried out in 2013 and to discuss contributive elements to the improvement of the practical classes development. The study included 3969 students and 396 teachers of 127 High Schools in 79 cities of the state. The current National Curriculum Guidelines for the secondary school served as the theoretical support, pointing to the research as a pedagogical principle and to its importance while arousing scientific curiosity in the students. It focused on a qualitative analysis achieved from quantitative data obtained through the application of a form by students and teachers. The data show that schools present well-structured and well-located laboratories; however, the practical classes are not being held, and when they are, they do not stimulate the interest in the investigation and in the increase of knowledge by the students. The analysis provides elements to discuss the factors that interfere in the development and quality of the practical classes.
\end{abstract}

Keywords: Laboratory; Practical classes; High School.

\title{
Resumen:
}

El artículo resulta de una encuesta realizada en 2014 en las escuelas estatales de Paraná que recibieron laboratorios de biología, química, física y matemáticas, enviados por el Gobierno Federal. El objetivo fue evaluar el uso de estos laboratorios y comparalos con los datos obtenidos en la encuesta realizada en 2013 y se analizar los elementos que contribuyen la mejoraranza de la eficacia de las clases prácticas. Contemplado 3.969 estudiantes y 397 profesores de enseñanza secundaria en 127 escuelas ubicadas en 79 municípios. Teve como soporte teórico las Directrices Curriculares Nacionales actuales para la educación secundaria, que apuntan a la investigación como un principio pedagógico y la importancia de despertar la curiosidad científica en estudiantes. Priorizado un análisis cualitativo de los datos cuantitativos obtenidos a través del formulario contestado por los estudiantes y profesores. Los datos muestran que las escuelas cuentan con laboratorios bien estructurados en el espacio, sin embargo, no son retenidos en las clases prácticas, y cuando se hacen, no estimular el interés en la investigación y el desarrollo de los conocimientos de los estudiantes. El análisis proporciona elementos para analizar los factores que influyen en la eficacia y la calidad de las clases prácticas.

Palabras clave: Laboratorios; Clases prácticas; Enseñanza secundária. 


\section{Introdução}

Um dos principais motivos que influem negativamente no ensino da área de ciências da natureza (Biologia, Física e Química) e Matemática, está relacionado à falta de laboratório nas escolas. Segundo os professores, as aulas práticas no laboratório são imprescindíveis para tornar o ensino de ciências mais atrativo e significativo para os estudantes. Para Krasilchick (1987, p 49), "O laboratório é definido como o espaço apropriado para o trabalho prático, devendo ter condições de segurança e permitir a utilização durante e fora das aulas, para que os estudantes possam desenvolver os seus projetos".

Essa autora adverte que apesar de reconhecida a necessidade do laboratório, muitas escolas são construídas sem prever tal dependência, conforme constatou em pesquisa realizada. Em alguns casos, existe o laboratório, mas permanecem fechados por desinteresse de gestores e professores, ou ainda, por não existirem os materiais e equipamentos necessários ao seu funcionamento.

As aulas práticas realizadas em laboratório são essenciais para que os estudantes tenham um aprendizado eficiente e estruturado nas diversas disciplinas. São nessas aulas que os estudantes podem:investigar, avaliar resultados, testar experimentos, identificar problemas, propor soluções, enfim, são estimulados para novos desafios. De acordo com Dourado (2001), as atividades experimentais são importantes para o processo ensinoaprendizagem e devem estar adequadas às capacidades e atitudes que se pretende desenvolver nos estudantes.

As Diretrizes Curriculares Nacionais para o Ensino Médio - DCNEM (BRASIL, 2012), em seu artigo $5^{\circ}$ expressam que "O Ensino Médio em todas as suas formas de oferta e organização, baseia-se em formação integral do aluno, trabalho e pesquisa como princípios educativos e pedagógicos, respectivamente". Essas orientações instauram a necessidade de propiciar momentos pedagógicos nos quais os estudantes sejam instigados em sua curiosidade natural para buscar a compreensão dos fatos e fenômenos que o cercam, e assim, construir a sua autonomia de pensar e propor. Tais atividades podem ser estimuladas com maior propriedade, principalmente as relacionadas à investigação científica, quando existe um laboratório devidamente organizado no espaço escolar.

A utilização dos laboratórios no desenvolvimento dos processos educativos vem se intensificando, principalmente por proporcionar a relação teoria e prática,tão cara à compreensão do conhecimento em sua totalidade. No entanto, exige que os profissionais da educação tenham conhecimentos específicos para melhor aproveitamento das potencialidades dos equipamentos e para atender as especificidades do seu plano de trabalho, de acordo com a proposta curricular. Nas palavras de Freitas (2007, p. 28), é preciso, "[...] um conhecimento mais aprofundado sobre materiais e equipamentos didáticos atualmente em uso nas escolas".

Na perspectiva de estruturar as escolas com os laboratórios e incentivar a realização de aulas práticas, a Secretaria de Estado da Educação do Paraná - SEED estabeleceu convênio com o Ministério da Educação - MEC e com o Fundo Nacional de Desenvolvimento da Educação - FNDE, para a aquisição de laboratórios de Biologia, Física, Química, Matemática e Informática. Essa possibilidade foi colocada aos estados que possuem rede de ensino médio ou de educação profissional técnica de nível médio e tenham assinado o compromisso "Todos pela Educação". A seleção das escolas tem como base, entre outros aspectos, o índice de desenvolvimento humano - IDH local e o índice de desenvolvimento da Educação Básica - IDEB. Como contrapartida, cabe ao estado monitorar o programa no seu território.

Dessa forma, os laboratórios padrão MEC foram inseridos no plano de trabalho elaborado pelo Estado do Paraná, na dimensão de infraestrutura e recursos pedagógicos. As escolas selecionadas receberam em seus próprios endereços o laboratório encaminhado pelo MEC.

Foram contemplados 158 estabelecimentos da rede estadual de educação, situados em 89 municípios do Paraná, com um total de 376 laboratórios recebidos. Destes, 76 foram de biologia, 54 de física, 85 de Química, 64 de Matemática e 97 de Informática.O que representou um investimento aproximado de seis milhões de reais (TORRES JUNIOR, 2014). 
Nessa parceria, coube à SEED/PR fazer o acompanhamento da utilização desses laboratórios, no sentido de uma avaliação propositivaque visa detectar os possíveis problemas e propor, juntamente com gestores e professores, os encaminhamentos para a melhoria.

Em pesquisa de dissertação de mestrado sobre a situação dos laboratórios padrão MEC recebidos pelas escolas do Paraná, Torres Junior (2014) relata que dos 175 laboratórios pesquisados, 162 estavam devidamente instalados nas escolas, conforme informaram os gestores, porém, ao analisar o checklist dos itens de composição dos laboratórios, foi observado que alguns equipamentos ainda aguardavam instalação.

No presente trabalho, estabelecemos como objetivo central avaliar a utilização dos laboratórios, comparar com os dados obtidos na pesquisa realizada em 2013 e discutir elementos contributivos para a melhoria da efetivação das aulas práticas, com a participação dos estudantes e professores das escolas que receberam os referidos laboratórios.

O recurso metodológico adotado nessa pesquisa foramdois formulárioscontendo quatro questões fechadas e uma aberta, sendo um direcionado aos estudantes do Ensino Médio e o outro aos professores que ministram aulas nas disciplinas de Física, Química, Biologia e Matemática, em cada escola. A aplicação dos formulários foi realizada por funcionários dos Núcleos Regionais de Educação - NRE e reencaminhados à Coordenação de Projetos e Processos do Departamento de Educação e Trabalho - DET-SEED/PR.

O campo empírico a ser pesquisado incluiu somente as escolas que haviam recebido os laboratórios e nos quais os mesmos estavam devidamente instalados, isto é, prontos para serem utilizados.

A pesquisa contemplou 3.969 estudantes em 126 escolas, situadas em 79 municípios do Estado. Os estudantes participantes foram do Ensino Médio Integrado e Ensino Médio, sendo alguns do curso de Formação de Docentes e Programa Nacional de Integração da Educação Profissional com a Educação Básica na Modalidade de Educação de Jovens e Adultos - PROEJA. Totalizando o número de respondentes por laboratório temos: Biologia 881; Física 647; Matemática 1.247; Química 1194.

Contemplou também 397 professores que responderam questões similares às que foram realizadas aos estudantes, objetivando ampliar as informações sobre a utilização dos laboratórios, bem como, sobre as dificuldades em efetivar as aulas práticas. Foi priorizada uma análise qualitativa a partir dos dados quantitativos obtidos.

Essa pesquisa foi realizada também em 2013, mas nem todos as escolas foram as mesmas e houvevariação quanto àsquestões formuladas, o que impôs limites à comparação dos resultados nos dois anos pesquisados.

Assim, apresentamos nesse trabalho a totalidade da pesquisa realizada em 2014, contemplando estudantes e professores, e uma comparação de dois itens que foram compatíveis nos dois anos pesquisados: escolas participantes e frequência da utilização dos laboratórios.

\section{Utilização dos laboratórios padrão MEC a partir da avaliação dos estudantes}

Ao serem questionados sobre a frequência das aulas de laboratório, houve maior destaque para a alternativa "nunca tive aula de laboratório" do que para as alternativas que apontavam a frequência da utilização (Gráfico 1). Os dados apresentados nesse gráfico mostram que em torno de $50 \%$ dos estudantes que responderam sobre o laboratório de matemática afirmaram que nunca tiveram aula de laboratório. Dentre os respondentes dos quatro laboratórios (Física, Química, Biologia, Matemática) em torno de 10\% afirmaram ter aulas de laboratório com alguma frequência.

A disciplina de Química foi a menos mencionada na alternativa "nunca tive aula prática" citada por menos de $30 \%$ dos estudantes, fato que pode significar uma maior regularidade de aulas práticas nessa disciplina em relação às demais. 
Gráfico1. Frequência das aulas em cada laboratório padrão MEC. Questão: Você tem aula prática no laboratório? (estudantes)

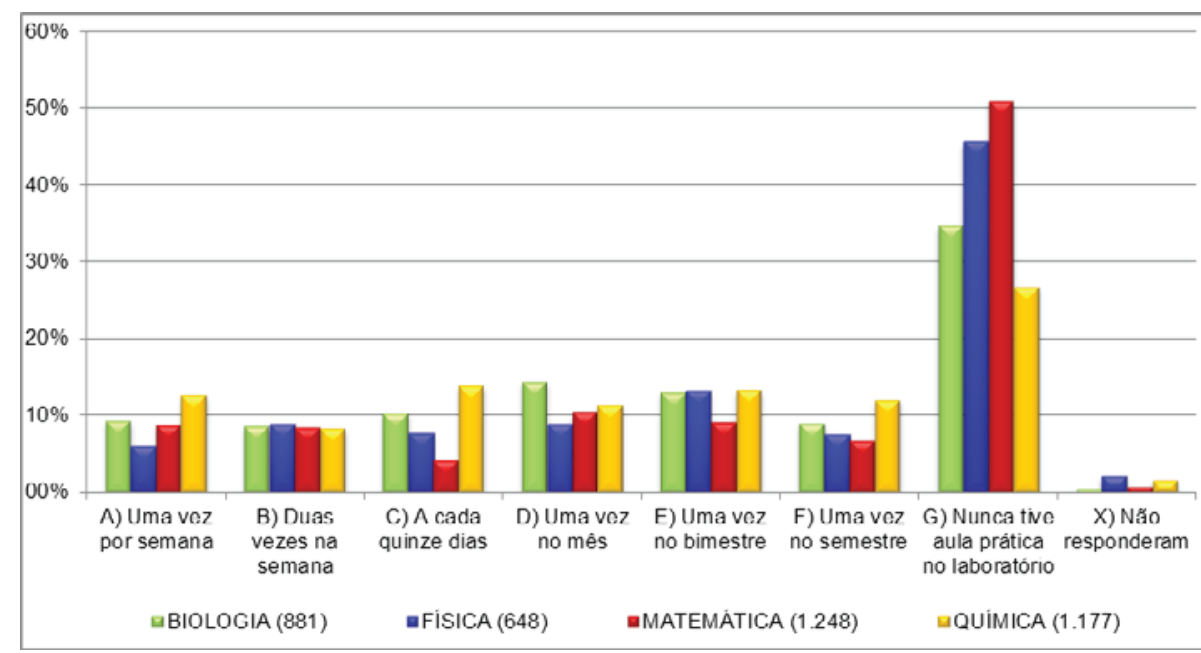

A importância das aulas de laboratórios para a assimilação do conhecimento foi destacada pelos estudantes em um percentual que variou entre 50\% e 60\% nas disciplinas de Biologia, Física, Química e Matemática, com destaque para Química que ultrapassou o percentual citado (Gráfico 2). No entanto, menos de 20\% avaliam as aulas de laboratório como sendo bem elaboradas e organizadas. Esses dados mostram que os estudantes reconhecem a importância das aulas práticas para a aprendizagem, apesar de a maioria ter pontuado que não está contando com esse recurso, conforme apontado na questão anterior, ou que quando ocorre, não atende ao esperado.

Gráfico 2. Avaliação dos estudantes sobre as aulas realizadas em cada laboratório padrão MEC. Questão: As aulas práticas que você tem no laboratório: (estudantes)

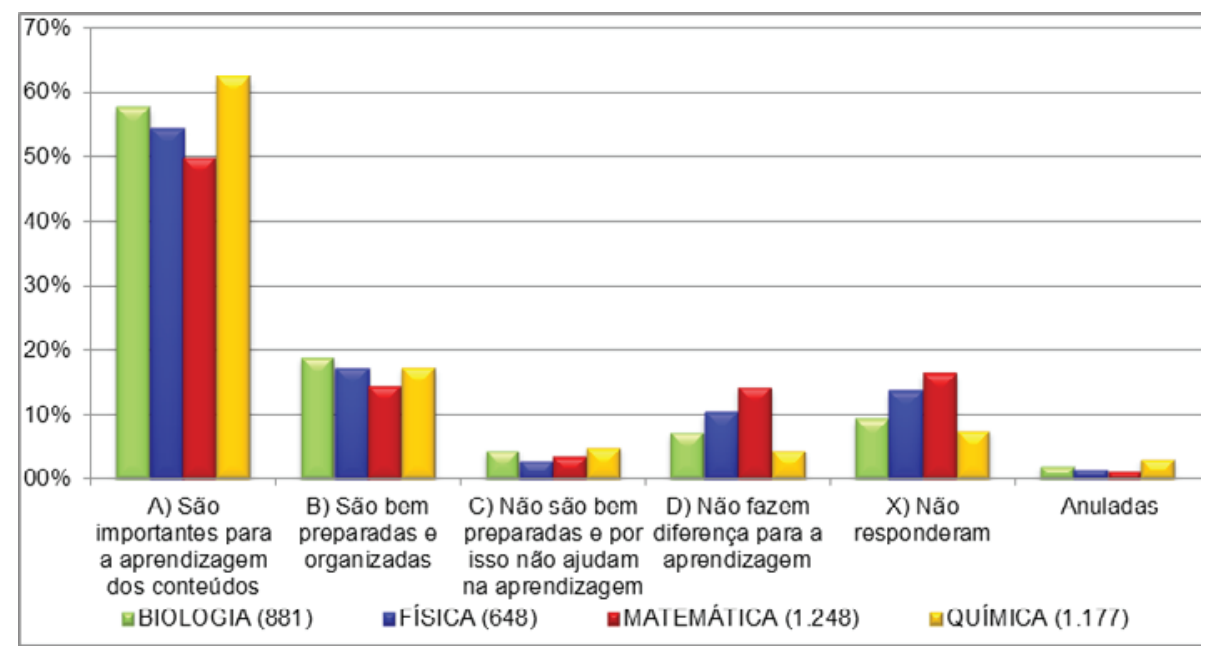

Mais de $40 \%$ dos estudantes destacaram que o laboratório de sua escola tem materiais e equipamentos suficientes para todos os estudantes, porém, em torno de 30\% manifestaram não ter conhecimento da existência de laboratório, uma vez que não estão tendo aulas práticas. Dentre os laboratórios que os estudantes desconhecem a existência, o de Matemática foi o mais mencionado (Gráfico 3). 
Gráfico 3. Avaliação feita pelos estudantes sobre a qualidade dos materiais e equipamentos em cada laboratório padrão MEC. Questão: O laboratório de sua escola: (estudantes)

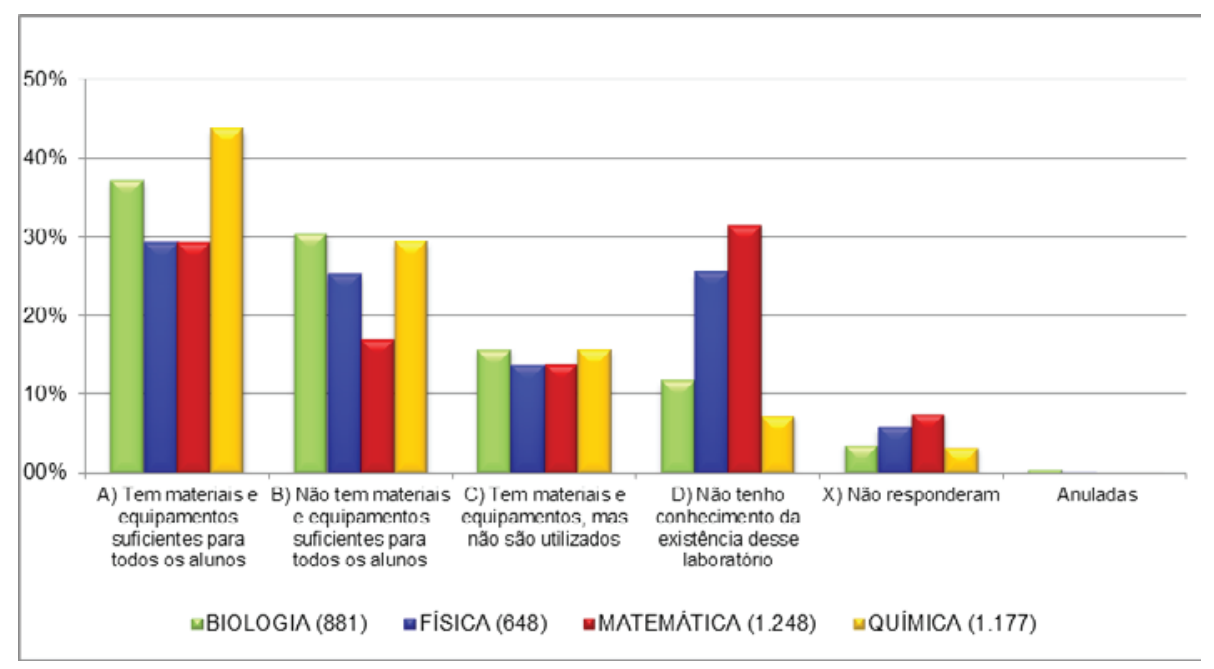

Em relação ao espaço do laboratório, $70 \%$ dos respondentes destacaram como ideal ao fim que se destina (Gráfico 4). Isso somado à questão anterior na qual afirmaram que os laboratórios apresentam materiais e equipamentos suficientes, se contrapõe a afirmação de $20 \%$ dos estudantes sobre o fato de o professor levar os materiais para demonstração em sala de aula ao invés de utilizar o laboratório. Ora, se o espaço físico é bom e se existem os materiais e equipamentos necessários por que não utilizar o laboratório? Tal dado instiga a reflexão dos motivos que possam justificar essa opção por parte dos professores.

Gráfico 4. Avaliação feita pelos estudantes sobre o espaço físico dos laboratórios padrão MEC. Questão: O espaço (sala) do laboratório específico do seu curso: (estudantes)

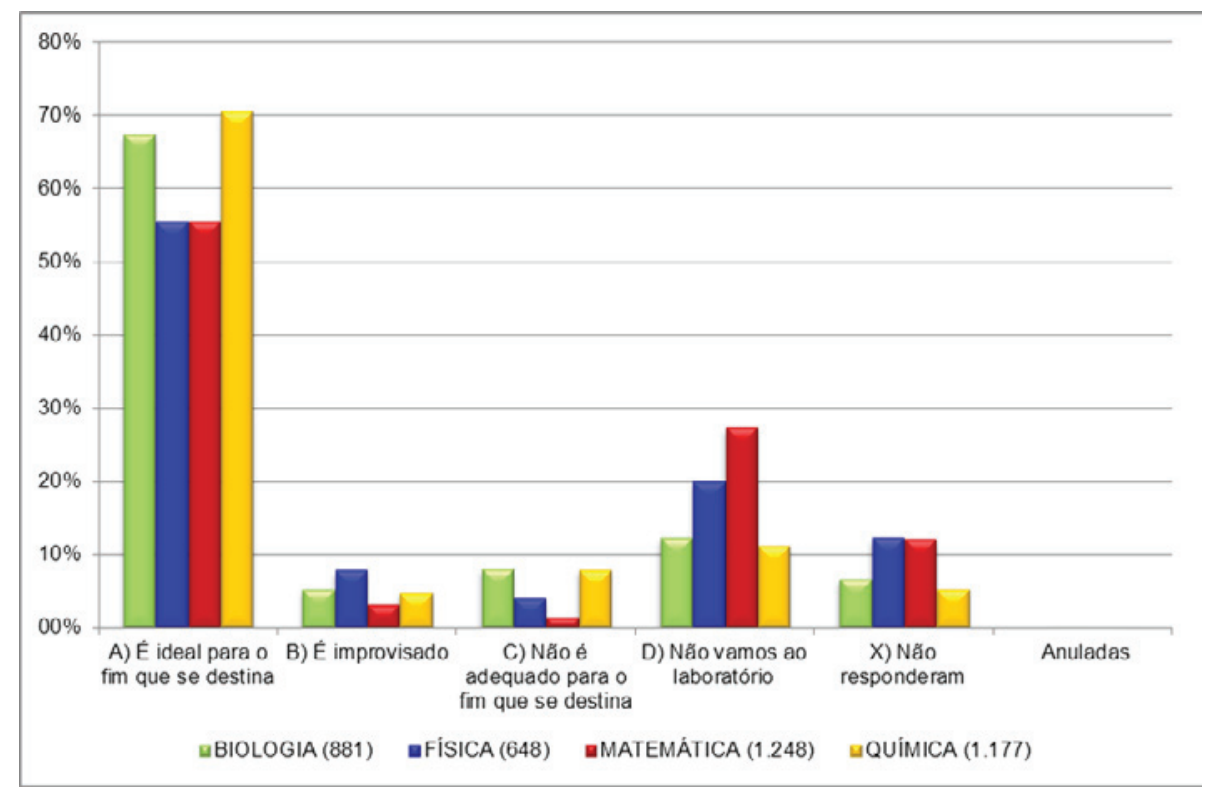




\section{Utilização dos laboratórios padrão MEC a partir da avaliação dos professores}

Entre $10 \%$ a $23 \%$ dos professores que participaram da pesquisa afirmaram não utilizar os laboratórios recebidos pelas escolas, o que difere do percentual de estudantes (50\%) respondentes da mesma questão, os quais mencionaram a ausência de aulas práticas no laboratório. 25\% dos professores disseram ministrar aulas de laboratório uma vez ao mês e uma vez no bimestre (Gráfico 5), enquanto que o percentual dos estudantes que responderam haver alguma frequência de aulas práticas ficou em torno de $10 \%$.

Gráfico 5. Avaliação dos professores sobre a utilização dos laboratórios padrão MEC. Questão: Você utiliza o laboratório para aulas práticas? (professores)

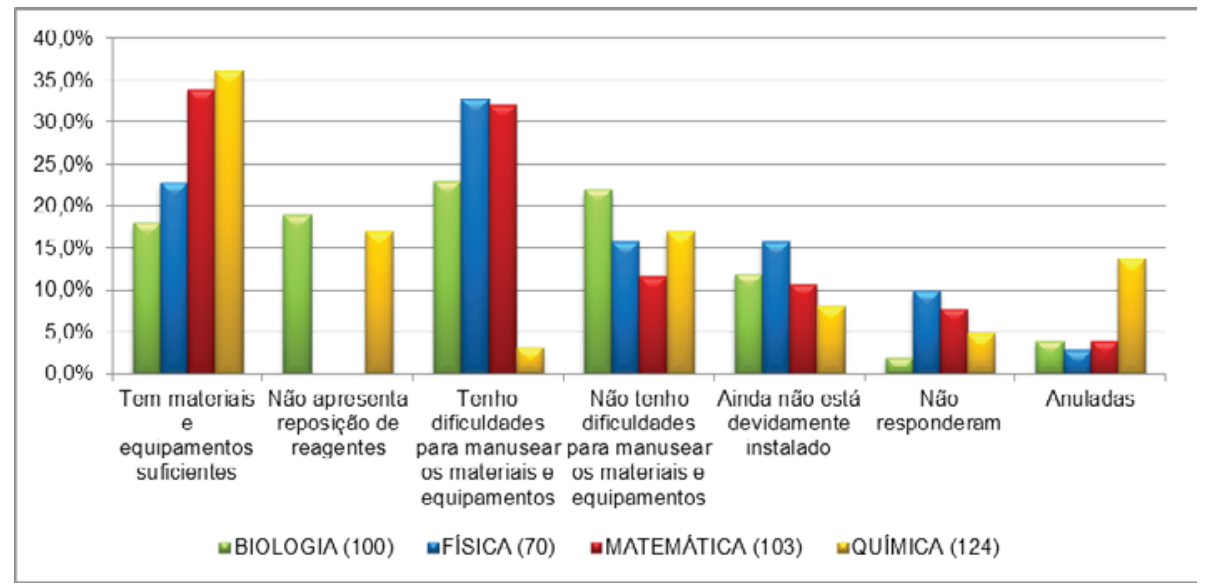

Assim como os estudantes, a maioria dos professores considerou a importância das aulas de laboratório para a aprendizagem (Gráfico 6), porém, destacaram a inviabilidade em efetivar essas aulas devido ao grande número de estudantes nas turmas. Esse indicativo pode justificar o fato de não estarem sendo realizadas aulas práticas no laboratório, apesar do mesmo estar devidamente estruturado na escola. Outro fato que merece a atenção é a dificuldade em relação ao manuseio dos equipamentos, mencionada pelos professores.

Gráfico 6. Avaliação dos professores sobre a importância das aulas nos laboratórios padrão MEC. Questão: As aulas práticas que você ministra no laboratório: (professores)

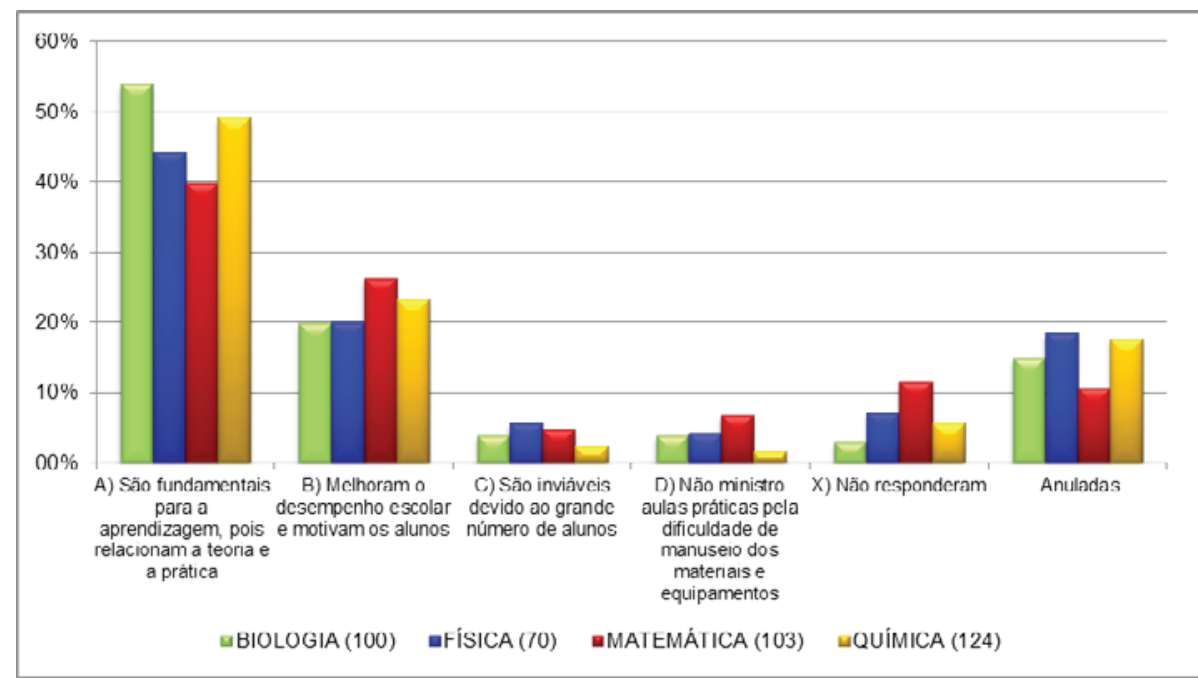


Ao avaliarem o laboratório padrão MEC da sua disciplina, mais de $20 \%$ dos professores reafirmaram que apresentam dificuldades para manusear os equipamentos de laboratório (Gráfico 7). Destacaram ainda, a falta de reposição de reagentes e o fato de alguns laboratórios ainda não terem sido instalados.

Gráfico 7. Avaliação dos professores sobre os laboratórios padrão MEC. Questão: Quanto ao laboratório padrão MEC da sua escola: (professores)

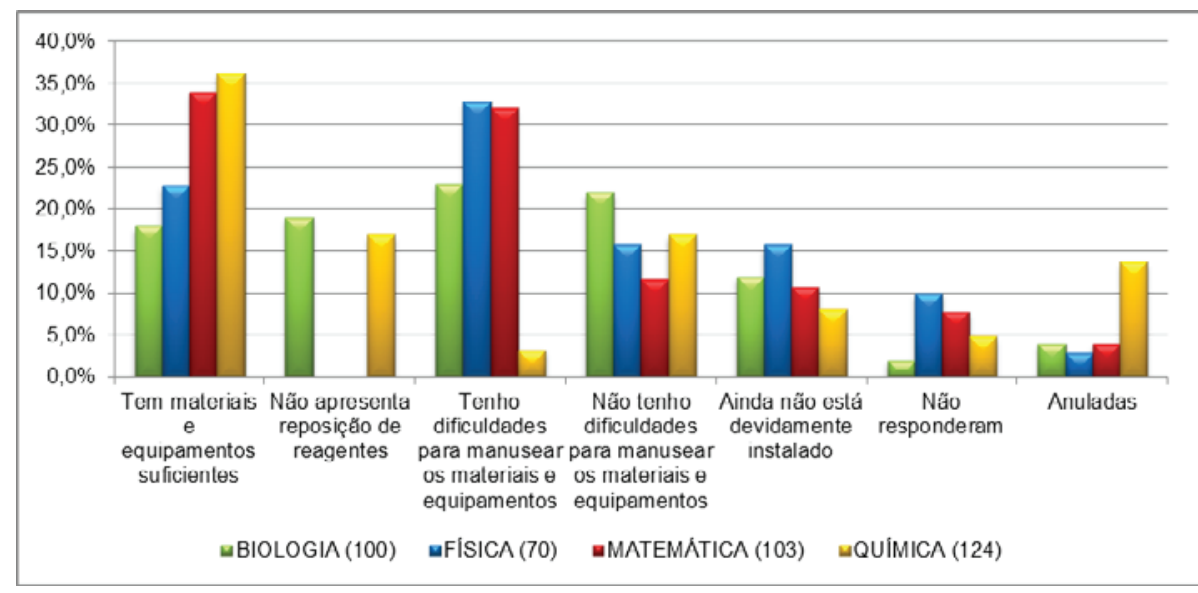

Com relação ao espaço físico destinado ao laboratório ficou evidente que é ideal para o fim que se destina (Gráfico 8), uma vez que foi destacado tanto pelos professores quanto pelos estudantes.

Gráfico 8. Avaliação dos professores sobre o espaço dos laboratórios padrão MEC. Questão: $O$ espaço (sala) do laboratório padrão MEC: (professores)

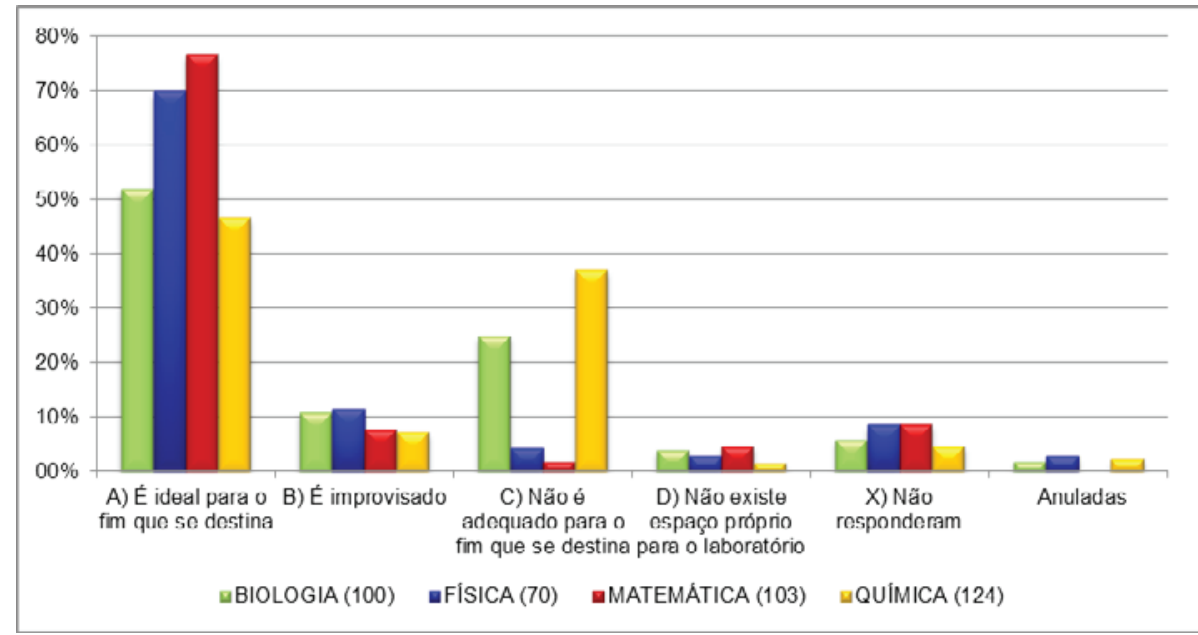

Comparação dos dados apresentados na pesquisa de 2013 e 2014

A pesquisa realizada em 2014 contemplou um número maior de escolas, municípios e NREsdo que a realizada em 2013, sendo que nesse ano 95,5\% das escolas que receberam laboratórios padrão MEC foram avaliadas, assim como, praticamente a totalidade dos municípios (98,8\%) (Tabela 1). Isso significa um total de 218 escolas pesquisadas, em 137 municípios, nos dois anos. O menor número de escolas e laboratórios pesquisados em 2013 deve-se ao fato do recebimento dos laboratórios não terem ocorrido ao mesmo tempo, poismuitos ainda não haviam sido recebidos. 
Tabela 1. Abrangência das pesquisas, para avaliação dos laboratórios padrão MEC, realizadas em 2013 e 2014.

\begin{tabular}{|c|c|c|c|c|}
\hline Quantidades & Avaliados 2013 & Avaliados 2014 & $\begin{array}{c}\text { Avaliados em } 2013 \mathrm{e} \\
2014\end{array}$ & Receberam laboratórios \\
\hline NRE & $25(86,2 \%)$ & $29(100 \%)$ & $24(82,8 \%)$ & 29 \\
\hline Municípios & $58(72,5 \%)$ & $79(98,8 \%)$ & $50(62,5 \%)$ & 80 \\
\hline Escolas & $91(68,4 \%)$ & $127(95,5 \%)$ & $73(54,9 \%)$ & 133 \\
\hline
\end{tabular}

Com relação à abrangência da pesquisa em termos de laboratórios avaliados, em 2014 foram avaliados em torno de $90 \%$ do total recebido no Paraná, enquanto que em 2013, o percentual avaliado ficou em torno de 70\% (Tabela 2). Dentre os laboratórios recebidos pelas escolas verifica-se que o de Química foi enviado em maior quantidade (85), seguido por Biologia (76), Matemática (64) e Física (54) (Tabela 1).

Tabela 2. Números e percentuais quantitativos de laboratórios padrão MEC avaliados em 2013 e 2014.

\begin{tabular}{|c|c|c|c|c|}
\hline Laboratórios & Avaliados 2013 & Avaliados 2014 & Avaliados em 2013 - 2014 & Total enviado pelo MEC \\
\hline Biologia & $54(71,1 \%)$ & $71(93,4 \%)$ & $41(53,9 \%)$ & 76 \\
\hline Física & $37(68,5 \%)$ & $48(88,9 \%)$ & $29(53,7 \%)$ & 54 \\
\hline Matemática & $43(67,2 \%)$ & $60(93,8 \%)$ & $38(59,4 \%)$ & 64 \\
\hline Química & $55(64,7 \%)$ & $79(92,9 \%)$ & $42(49,4 \%)$ & 279 \\
\hline Total & $189(67,7 \%)$ & $258(92,5 \%)$ & $150(53,8 \%)$ & $27 \%$ \\
\hline
\end{tabular}

A comparação dos dados da frequência de aulas práticas no laboratório, informado pelos estudantesmostra que em 2014 houve um aumento em relação a 2013, embora em termos percentuais esse aumento na utilização dos laboratórios tenha sido pouco significativo. Ao analisarmos o laboratório de Matemática, por exemplo, que em 2013 foi o mais mencionado pelos estudantes como não sendo utilizado (60\%), em 2014 esse percentual diminuiu para 49\%. Assim como em Física, diminuiu de 53\% para 50\%. Não se pode esquecer que nessas disciplinas, principalmente em Matemática, o laboratório é uma novidade, não fazia parte da realidade escolar anteriormente. O ensino da matemática do Ensino Médio sempre ocorreupor meio de resolução de exercícios em sala de aula, e não de forma prática em laboratório. Dessa forma, não pode causar estranheza o fato de estarem sendo pouco utilizados, o que também não justifica que continuem sem uso.

Em relação à Biologia e Química, são disciplinas mais relacionadas à experimentação, embora isso não signifique que as aulas práticas ocorram a contento, uma vez que é histórica a precariedade de laboratórios e equipamentos na rede pública. Fato que fica evidente no gráfico, uma vez essas duas disciplinas foram as menos mencionadas na alternativa "não é utilizado".

As demais alternativas referentes à utilização do laboratório: uma vez por semana; uma vez por quinzena; uma vez por mês; uma vez por bimestre, uma vez por semestre; uma vez por ano, pode-se perceber que, de uma forma geral, ocorreu uma variação para maior nosíndices percentuais obtidos em 2014, o que também indica um aumento na utilização dos laboratórios (Gráfico 9). 


\section{Gráfico 9. Dados comparativos da frequência de aulas práticas nos laboratórios padrão MEC, informado pelos estudantes, em 2013 e 2014}

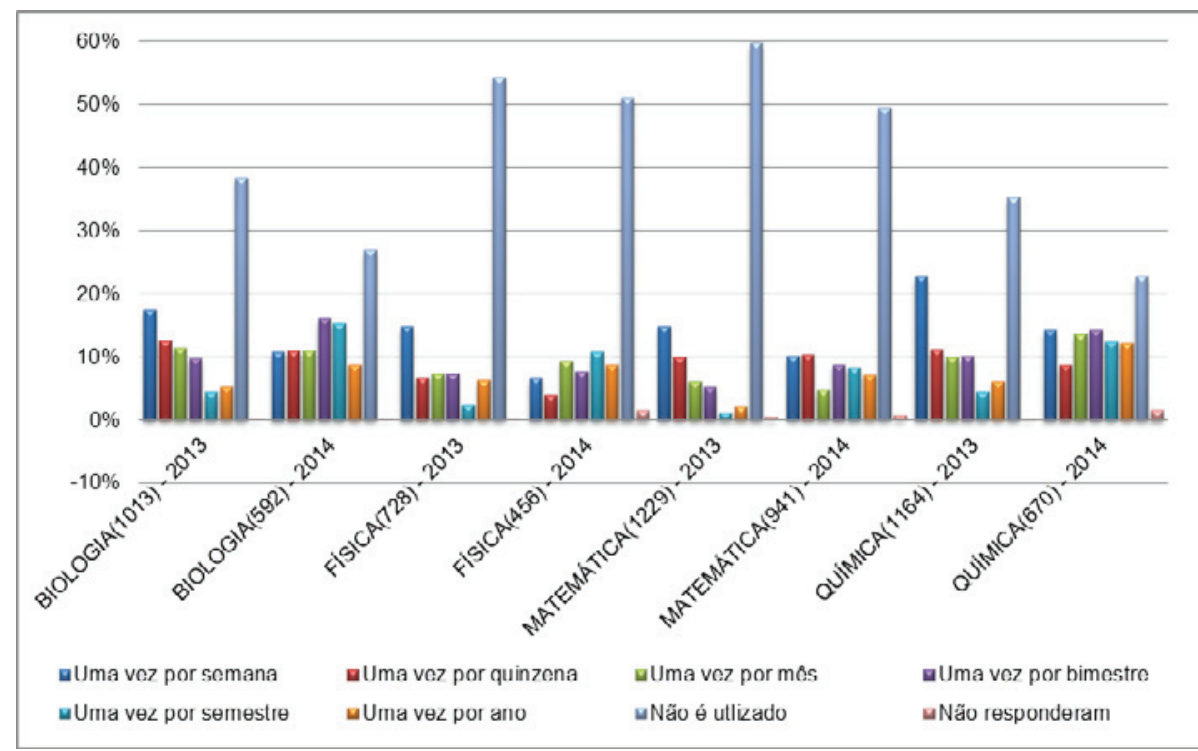

O fato de ter sido observado uma maior utilização dos laboratórios em 2014, embora pouco significativa, pode estar relacionado ao esforço individual de alguns professores em aproveitar esse recurso disponível na escola, uma vez que afirmaram reconhecer a importância das aulas de laboratório para a assimilação do conhecimento pelos estudantes.

\section{Discussão dos dados}

A pesquisa realizada sobre a utilização dos laboratórios padrão MEC mostra que as escolas apresentam materiais e equipamentos de laboratórios devidamente instalados em espaço físico adequado. Por outro lado, revela que os laboratórios não estão sendo utilizados, e que alguns estão totalmente ociosos, ao ponto dos estudantes que participaram da pesquisa não saberem da sua existência.

Portanto, fica claro que a implantação e estruturação dos laboratórios nas escolas não significa que as aulas práticas estarão sendo efetivadas, embora a existência dos mesmos seja de grande importância para iniciar um processo organizado de investigação científica no qual a pesquisa seja um dos princípios pedagógicos, como prezam as DCNEM (BRASIL, 2012).

Os dados apresentados remetem a um conjunto de fatores que podem interferir na efetivação das aulas práticas, como foi citado pelos professores: número excessivo de estudantes nas turmas; impossibilidade de desmembramento das turmas para as aulas práticas; falta de um funcionário para cuidar dos materiais e equipamentos e auxiliar no preparo das aulas, etc. Esses fatores, somados às dificuldades apontadas pelos professores para o manuseio dos materiais e equipamentos se colocam como impeditivos para a efetivação das aulas práticas e precisam ser administrados pela gestão escolar.

No tocante ao número de estudantes, a legislação que normatiza a composição de turmas, Resolução n 4.527 (PARANÁ, 2011), em vigência no estado, expressa que as turmas de Ensino Médio devem ser constituídas com o número de 35 a 40 estudantes, porém o documento não menciona o número de estudantes em aulas de laboratório.

De acordo com o que foi discutido e aprovado na Conferência Nacional de Educação - CONAE, realizada em novembro de 2014, as turmas de Ensino Médio devem apresentar no máximo 30 estudantes, o que demanda de uma reestruturação legal por parte de cada estado da federação. Entretanto, da mesma forma que o documento 
estadual, refere-se somente às turmas regulares da escola e não faz nenhuma menção a composição das turmas para as aulas de laboratório.

Pedagogicamente seria impossível desenvolver atividades práticas e orientar a observação, investigação e manuseio de equipamentos em uma turma com o mesmo número de estudantes das aulas teóricas, contudo, na falta de um amparo legal em relação a essa questão, é necessário haver uma organização da própria gestão escolar para assegurar a efetivação das aulas práticas com qualidade.

Outro aspecto importante a ser considerado na constituição das turmas atendidas no laboratório é a segurança. O número excessivo de estudantes dificulta os cuidados necessários quanto às normas existentes, o que poderia por em risco a saúde e o bem estar dos estudantes pelo contato com ácidos, gases e outros produtos que requerem cuidados. Além disso, deve ser considerado também o despreparo de grande parte dos professores para organizar e ministrar as aulas práticas, conforme mencionado por eles mesmos, fato que remete à necessidade de formação continuada.

Torna-se evidente que em uma primeira instância, o professor precisa saber utilizar os materiais e equipamentos, assim como, é imprescindível que conheça os recursos metodológicos necessários para estabelecer a relação teoria e prática como partes indissociáveis do conhecimento. A necessidade de um profissional responsável pelo laboratório que possa auxiliar durante as aulas práticas foi apontada pelos professores como sendo de grande importância para uma boa utilização e manutenção do laboratório. Além disso, é preciso estabelecer uma forma racional e coerente de desmembramentos das turmas para as aulas práticas de laboratório. Contudo, deve-se considerar o número escasso de professores em disciplinas como Química e Física e também algumas disciplinas técnicas, o que poderia ser agravado com o desmembramento, uma vez que aumenta o número de aulas e consequentemente, requer um número maior de professores. Porém, esse fato não pode ser o motivo para que o laboratório se torne ocioso na escola, devidoa sua importância e ao dinheiro público investido.

A comparação da utilização dos laboratórios, nos dois anos pesquisados, mostra a que a frequência das aulas práticas está muito aquém do que poderia acontecer, considerando a representatividade dos laboratórios em termos de investimento e de benefícios que poderiam ser direcionados ao conhecimento dos estudantes.

Isso demanda providências por parte dos gestores no sentido de assegurar o bom aproveitamento dos laboratórios em prol da aprendizagem dos estudantes, com potencialidade tanto para conferir cientificidade à práxis do Ensino Médio, quanto para tornar as aulas mais agradáveis e interessantes aos estudantes.

\section{Considerações finais}

A proposta de avaliação dos laboratórios padrão MEC nas escolas estaduais ocorreu na perspectiva de detectar os problemas que impedem a efetivação das aulas práticas com qualidade e segurança e propor medidas que possam contribuir para uma melhor utilização dos mesmos.

É importante esclarecer que o sentido dessa avaliação não foi vigiar ou encontrar culpados, ou ainda, compilar uma série de dados e deixá-los encerrados em arquivos. Mas divulgar esses dados aos interessadossejam: os professores, gestores, estudantes e comunidade escolar como um todo, para que juntos possam discutir e encontrar soluções possíveis aos problemas encontrados, portanto, com um caráter avaliativo e propositivo.

A pesquisa revelou que as escolas estaduais do Paraná, que foram avaliadas,apresentam laboratório devidamente equipado, em espaço físico adequado, mas que as aulas práticas não estão sendo realizadas, e quando se realizam, não ocorrem de maneira adequada de forma a contribuir para o processo ensino aprendizagem. A contradição está no fato de que a aquisição dos laboratórios é resultado de reinvindicações dos próprios professores e gestores junto às instâncias superiores, portanto, o esperado é que fossem mais utilizados e aproveitados como um recurso importante para dinamizar as aulas nas referidas disciplinas.

A comparação da frequência de realização das aulas práticas em 2014 com a pesquisa realizada em 2013 
mostrou que houve uma melhora em 2014, porém pouco significativa em termos numéricos e percentuais, o que evidencia que persistem os problemas que dificultam a realização das aulas práticas nas escolas.

A análise dos apontamentos feitos por estudantes e professores permitiu compreender que existe um conjunto de fatores que interferem na efetivação e qualidade das aulas práticas, dentre eles: o número de estudantes nas turmas; aimpossibilidade de desmembramento para as aulas práticas;afalta de um profissional de apoio nos laboratórios para ajudar no preparo das aulas e na manutenção. Soma-se a isso, a fragilidade da formação de grande parte dos professores que gera despreparo para o manuseio dos materiais e equipamentos.

O desvelamento de tal situação a partir dessa pesquisa constitui elementos importantes para repensar as aulas práticas de laboratório e as formas possíveis de reorganizaçãodesse componente curricular nas escolas. Fornece ainda,dados que contribuem para consolidar o princípio pedagógico da pesquisa, tão caro a alfabetização científica para leitura da realidade pelos estudantes.

\section{Referências}

BRASIL. Resolução CNE/CEB n 2 de 30 de janeiro de 2012. Define Diretrizes Curriculares Nacionais para o Ensino Médio. Diário Oficial da República Federativa do Brasil, Brasília, 31 de janeiro de 2012, Seção 1, p. 20. Disponível em http://pesquisa.in.gov.br/imprensa/jsp/visualiza/index.jsp?jornal=1\&pagina=20 \&data=31/01/2012 Acesso em: out. 2014.

DOURADO, L. Trabalho Prático, trabalho laboratorial, trabalho de campo e trabalho experimental no ensino de ciências: contributo para uma clarificação de termos. In: Ensino experimental das ciências. Lisboa, 2001, p. 13-18.

FREITAS, O. Equipamentos e materiais didáticos. Brasília: Universidade de Brasília, 2007. 132 p.

KRASILCHIK, M. O professor e o currículo de ciências. Temas Básicos de educação e ensino. Ed. EPU. São Paulo, 1987.

PARANÁ. Secretaria de Estado da Educação. Resolução Nº 4527/2011 - GS/SEED. Fixa número de estudantes para efeito de composição de turmas nas Instituições Escolares. Curitiba, 2011.

TORRES JUNIOR, C. V. Implantação dos laboratórios básicos padrão MEC/FNDE na rede pública do Estado do Paraná pelo Programa Brasil Profissionalizado. Dissertação (Mestrado Profissional). Universidade Federal de Juiz de Fora - MG, 2014.

Recebido em Novembro de 2015 | Aprovado em Dezembro de 2015 